\title{
De los derechos de los grupos indígenas en el marco internacional*
}

\author{
[Artículos]
}

Omar Antonio Herrán Pinzón **

Jacqueline Blanco Blanco ${ }^{* * *}$

Recibido: 10 abril de 2021

Aceptado: 6 de mayo de 2021

Citar como:

Herrán Pinzón, O. A. y Blanco Blanco, J. (2021). De los derechos de los grupos indígenas en el marco internacional. Revista IUSTA, (55).

https://doi.org/10.15332/25005286.6851

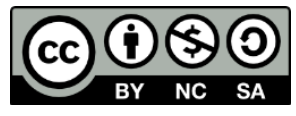

\section{Resumen}

A partir de un método de investigación histórico, se realiza un recorrido legislativo por el derecho de los indígenas en el campo internacional,

\footnotetext{
* Este artículo es resultado del proyecto de investigación "Mutilación genital femenina, diversidad cultural y universalidad de los derechos humanos" (INV-DER-2556), desarrollado durante el 2018 en la Universidad Militar Nueva Granada, Bogotá, Colombia, adscrito al grupo de investigación Derecho Público, clasificado en la categoría B de Minciencias.

** Docente de la Facultad de Derecho de la Universidad Militar Nueva Granada, sede Bogotá. Investigador del grupo Derecho Público, línea de Derecho Penal, del Centro de Investigaciones Jurídicas, Políticas y Sociales de la Facultad de Derecho. Abogado de la Universidad Militar Nueva Granada y magíster en Derecho Procesal Penal de la misma institución. Correo electrónico: omar.herran@unimilitar.edu.co. ORCID:

https://orcid.org/0000-0001-7731-0996

*** Doctora en Sociología Jurídica e Instituciones Políticas, magíster en Historia, especialista en Filosofía del Derecho y Teoría Jurídica, y licenciada en Ciencias Sociales. Docente e investigadora de la Facultad de Derecho de la Universidad Militar Nueva Granada. Correo electrónico: jacqueline.blanco@unimilitar.edu.co. ORCID: https://orcid.org/0000-0001-7148-4856
} 
contenido en el reconocimiento de la diversidad sociocultural y el posible conflicto que conlleva esta realidad aprendida constitucionalmente. Se discute la importancia de la diversidad sociocultural de las comunidades indígenas y su cosmovisión frente a prácticas que atentan contra la dignidad humana - como la mutilación genital femenina-, que concentran los intereses actuales de la comunidad internacional.

Palabras clave: derechos, globalización, igualdad, justicia, movimientos indígenas.

\section{The rights of indigenous groups in the international framework}

\section{Abstract}

Based on a historical research method, a legislative review of the rights of indigenous people in the international framework is made, based on the recognition of socio-cultural diversity and the possible conflict that this constitutionally learned reality entails. The importance of the sociocultural diversity of indigenous communities and their worldview in the face of practices that violate human dignity - such as female genital mutilation-, which are the current focus of interests of the international community, is discussed.

Keywords: rights, globalization, equality, justice, indigenous movements.

\section{Dos direitos dos grupos indígenas no contexto internacional}

\section{Resumo}

A partir de um método de pesquisa histórico, é realizado um percorrido legislativo pelo direito dos indígenas no campo internacional, contido no reconhecimento da diversidade sociocultural e do possível conflito que implica essa realidade aprendida constitucionalmente. É discutida a 
importância da diversidade sociocultural das comunidades indígenas e sua cosmovisão ante práticas que atentam contra a dignidade humana como a mutilação genital feminina -, que concentram os interesses atuais da comunidade internacional.

Palavras-chave: direitos, globalização, igualdade, justiça, movimentos indígenas.

\section{Introducción}

En el contexto actual, caracterizado por la armonización del mundo como consecuencia de la globalización cultural y económica propiciada por la apertura del capital, la activación de la progresiva interdependencia entre países, la conformación de bloques regionales y el surgimiento de economías emergentes, en Colombia y en otros países surgen movimientos que reivindican la autonomía y la diversidad étnica y sociocultural (Sierra, 1997, p. 131).

Consideramos que la solución de los problemas que aquejan a los pueblos indígenas en la región debe partir del ámbito interno de los Estados, con decisiones políticas y judiciales que comprometan a toda la sociedad. En Colombia, el reconocimiento legal de los derechos de las comunidades étnicas se formalizó con la Constitución Política de 1991, que, sin dejar de lado los compromisos internacionales que se dan por la aplicación del bloque de constitucionalidad, logró el amparo y el respeto por la diversidad de los derechos de los pueblos indígenas, un asunto que debe estar presente en la agenda pública de los gobiernos de turno (Bahamón, 2020).

En este sentido, la jurisprudencia del Sistema Interamericano de Protección de los Derechos Humanos (SIDH) ha avanzado en cuanto a las garantías de identidad y desarrollo cultural a través del fortalecimiento de los derechos de los pueblos indígenas. La preocupación por su situación 
histórica y amparo viene construyéndose desde la década de 1950, pues hay una consolidación discursiva importante enmarcada en el Convenio 107 de 1957 (OIT, s. f.), que hace referencia a la "protección e integración de las poblaciones indígenas y de otras poblaciones tribuales y semitribuales en los países independientes sobre la protección de las poblaciones indígenas y tribales".

Siguiendo con lo anterior, el presente artículo se orienta por una pregunta problema: ¿el Estado tiene legitimidad, de conformidad con el derecho internacional reconocido a las comunidades indígenas, para hacer frente a las posiciones de reconocimiento de la diversidad sociocultural que implican la imposibilidad de intervenciones por su parte en prácticas ancestrales como la ablación genital femenina u otras que compongan tradiciones arraigadas en el grupo humano, así estas puedan constituir desde la óptica internacional violaciones a los derechos humanos?

Para responder a esta inquietud, se identificarán los derechos reconocidos a las mujeres de los pueblos indígenas en la actualidad y cómo estos permiten entablar un diálogo bipartito entre las autoridades indígenas y el Gobierno nacional, en aras de modificar usos y costumbres - como la ablación genital femenina-, sin que esto genere una violación a su identidad cultural.

\section{Derechos humanos y derechos étnicos}

En el Pacto Internacional de Derechos Civiles y Políticos, un tratado multilateral general que reconoce los derechos civiles y políticos de diversas comunidades y establece mecanismos para su protección y garantía, adoptado por la Asamblea General de las Naciones Unidas en 1966, se asume que: 
En los Estados en que existan minorías étnicas, religiosas o lingüísticas, no se negará a las personas que pertenezcan a dichas minorías el derecho que les corresponde, en común con los demás miembros de su grupo, a tener su propia vida cultural, a profesar y practicar su propia religión y emplear su propio idioma. (Acnudh, s. f., Artículo 27, p. 9)

Por su parte, Willem Assies (2000) manifiesta que el Artículo citado ha sido la base de disposiciones favorables para las comunidades indígenas.

En 1985, por ejemplo, la Comisión invocó este artículo en favor de los yanomami en Brasil. Según la Comisión, las invasiones de las tierras ancestrales de los yanomami no solamente amenazaron su bienestar físico sino también su cultura y sus tradiciones. La Comisión, por lo tanto, recomendó que el gobierno brasilero proceda a asegurar las fronteras de una reserva para los yanomami. Bajo presión internacional, una reserva de 9 millones de hectáreas fue creada en 1992 en el contexto de las preparaciones para la Cumbre de la Tierra en Río de Janeiro. (Assies, 200, s. p.)

Por otro lado, se observa que la Organización de las Naciones Unidas (ONU) ha decidido abordar las temáticas de reconocimiento y respeto de lo propio, como se evidencia en la conferencia celebrada en El Cairo en 1994 sobre población y desarrollo, donde más de un centenar de países suscribieron un conjunto de recomendaciones y metas comunes, consolidadas en el programa de acción de la conferencia (Unesco, 2004). De acuerdo con lo anterior, las metas fijadas se orientaron a partir de los diversos conocimientos de las necesidades de hombres y mujeres. Particularmente en América Latina, los objetivos, los alcances y las recomendaciones para la acción se definieron en el seno del Comité Especial sobre Población y Desarrollo del periodo habitual de sesiones de la Comisión Económica para América Latina y el Caribe (Cepal, 2010). 
La conquista de los derechos de los pueblos indígenas y su reconocimiento en el ámbito internacional contrasta con las frecuentes situaciones en las que los grupos sociales toman conciencia de sus problemas de existencia, al verse enfrentados a coyunturas que no pueden evadir. El aumento de los problemas económicos y las amenazas a las que se exponen despiertan una dialéctica entre su humanización y deshumanización, por lo tanto, la Declaración Universal de los Derechos Humanos se sitúa como un referente principal para empezar a entender la evolución y el desarrollo de los pueblos indígenas, además de señalar a los Estados, cualquiera sea su régimen político e ideológico, su obligación de respetarlos.

Esto quiere decir que las comunidades indígenas pueden apelar permanentemente a la Declaración Universal de los Derechos Humanos con el objetivo de que sus exigencias sean tomadas en cuenta por los gobiernos nacionales e internacionales (Stavenhagen, 2004, p. 16).

Una de las principales fuentes de derechos reconocidos es el Convenio 169 de la OIT (2014). En el documento se observa la producción de efectos jurídicos inmediatos en el marco constitucional interno de los países latinoamericanos. Se asumen nociones fundamentales referidas a la esfera de los derechos colectivos frente al predominio de los derechos individuales, además, los pueblos indígenas se definen en atención a su origen histórico, por lo que estos suponen un ser que se afirma a sí mismo y a la persistencia de todas o parte de sus instituciones sociales, económicas, culturales y políticas. De esta manera, la reconstrucción del ser tiene su fundamento mismo en la concepción de la tierra y el significado que para estas comunidades indígenas representa (Gómez, 1998, p. 48).

La "solución de esta tensión entre territorios que se presumen excluyentes $\mathrm{y}$, por tanto, deben articularse mediante instrumentos de nosubordinación, es el centro de la lucha indígena contemporánea” 
(Houghton, 2008, p. 176). Asimismo, de acuerdo con el contexto internacional, la Declaración de las Naciones sobre los Derechos de los Pueblos Indígenas (ONU, 2008), en su Artículo 4, establece que:

Los pueblos indígenas, en ejercicio de su derecho a la libre determinación, tienen derecho a la autonomía o al autogobierno en las cuestiones relacionadas con sus asuntos internos y locales, así como a disponer de medios para financiar sus funciones autónomas. (p. 5)

De esta manera, se formula una concepción filosófica y legal de declaración del carácter de los pueblos, sin limitaciones a sus derechos a la libre determinación, pues se asumen como expresión de su autonomía, sin que sean contrarios a la normativa interna de cada país, y por supuesto a los estándares internacionales.

En línea con lo expuesto, y retomando el Convenio 169, podemos interpretar en su Artículo 3 que la normativa no hace distinción por motivos de género. Así, el Proyecto de Declaración Americana sobre Derechos de los Pueblos Indígenas, que había sido acordado desde el 18 de noviembre de 1989, y cuya discusión culminó 18 años después con la Declaración Americana sobre los Derechos de los Pueblos Indígenas en el 2007, deja claro en su Artículo 22, numeral 2 que "[l]os Estados adoptarán medidas, junto con los pueblos indígenas, para asegurar que las mujeres y los niños indígenas gocen de protección y garantías plenas contra todas las formas de violencia y discriminación" (ONU, 2007, p. 7). En el mismo sentido, en la segunda sesión celebrada el 14 de junio de 2016, se resalta la "[i]gualdad de género: las mujeres indígenas tienen derechos colectivos indispensables para su existencia, bienestar y desarrollo integral como pueblos" (OEA, 2016, s. p.).

Sin embargo, en las últimas dos décadas se produjo en América Latina un movimiento constitucional de reconocimiento de los derechos de los 
pueblos indígenas, representado por Nicaragua, Colombia, Paraguay, Perú, México, Bolivia, Brasil, Guatemala, Panamá y Ecuador [...] Estas Constituciones admiten el derecho de esos pueblos a su identidad étnica y cultural, dando paso así a la aceptación del pluralismo étnico-cultural en los Estados latinoamericanos. (Cujabante, 2014, p. 211)

A continuación, se presenta el marco constitucional de algunos países latinoamericanos que reconocen el derecho a la tierra de los pueblos indígenas como factor fundamental para el respeto de las formas especiales de su jurisdicción (tabla 1). De igual manera, algunos Estados como México garantizan que las mujeres y los hombres indígenas disfrutarán y ejercerán su derecho de votar y ser votados en condiciones de igualdad. Las demás legislaciones hacen referencia a los derechos de las mujeres en igualdad con los hombres, pero de forma genérica; no se observa, como en el caso particular mexicano, una distinción entre hombres y mujeres indígenas. Sin embargo, el reconocimiento a la naturaleza pluricultural de sus naciones y las garantías para ejercer y fortalecer su identidad son aspectos generalizados.

Tabla 1. Marcos constitucionales de países latinoamericanos

\begin{tabular}{|c|c|c|}
\hline País & Año de constitución política & Artículos \\
\hline Nicaragua & 1986, 2014 & $\begin{array}{c}2,3,5,121,107,121,160,177 \\
181 .\end{array}$ \\
\hline Brasil & 1988 & $\begin{array}{c}22,49,109,129,176,210,215, \\
231 .\end{array}$ \\
\hline Paraguay & 1992 & $62,63,64,65,66,67,140,268$ \\
\hline Bolivia & 1994 & 171. \\
\hline Ecuador & 1998 & $\begin{array}{c}1,24,83,84,191,224,228,241, \\
275 .\end{array}$ \\
\hline México & 1992 & $\begin{array}{l}2,3,4,27,28,115 \text {, artículos } \\
\text { transitorios } 3,4,13 .\end{array}$ \\
\hline Colombia & 1991 & $\begin{array}{c}96,171,246,286,321,329,330 \\
351, \text { artículo transitorio } 56 .\end{array}$ \\
\hline
\end{tabular}

Fuente: elaboración propia. 
En conclusión, para el caso de Colombia podemos resumir la normatividad aplicable a los pueblos indígenas de la siguiente manera: 1) la Convención 169 de la OIT sobre Pueblos Indígenas y Tribales, incorporada mediante la Ley 21 de 1991, conforme a la Sentencia C-068 de 2013. Las disposiciones constitucionales y las regulaciones de la Convención formarían un bloque de constitucionalidad en virtud de lo previsto en el Artículo 93 de la Constitución Política. 2) La Ley 89 de 189o, "por la cual se determina la manera como deben ser gobernados los salvajes", refiriéndose a los indígenas, en el hecho de que se reduzcan a la vida civilizada. 3) El Decreto 2001 de 1988, reglamentario de la Ley 30 de 1988, que establece definiciones claras de los términos relativos a territorios y organización indígena. Y 4) la Declaración de las Naciones Unidas sobre los Derechos de los Pueblos Indígenas, aprobada por la Asamblea General de las Naciones Unidas en 2007, y que fomenta los derechos de los pueblos indígenas.

\section{Territorio y libre determinación}

Para lograr el amparo universal de los derechos humanos a las comunidades indígenas, el derecho internacional precisa apartes sobre el derecho de la "libre determinación" y "autodeterminación". En los dos pactos adoptados por la Asamblea General de la ONU en 1966, se ratifica que: "Todos los pueblos tienen el derecho a la libre determinación, en virtud de este derecho establecen libremente su condición política y proveen asimismo a su desarrollo económico, social y cultural” (Acnudh, s. f., Artículo 1, p.1).

En los últimos años, la disertación de los movimientos indígenas que surgieron en lo extenso del continente se ha concentrado en la libre determinación o en la autonomía, garantía fundamental que debe desarrollarse como requisito sine qua non en el territorio, como soporte esencial para un avance de autodeterminación y para la conformación de 
sus propias formas de gobierno. Las disposiciones jurídicas que protegen lo anteriormente indicado se encuentran en el Artículo 103 de la Carta de las Naciones Unidas (1945), donde se refiere que: "En caso de conflicto entre las obligaciones contraídas por los miembros de las Naciones Unidas en virtud de la presente Carta y sus obligaciones contraídas en virtud de cualquier otro convenio internacional, prevalecerán las obligaciones impuestas por la presente Carta" (ONU, 1945 [2020], s. p.).

Este marco jurídico se compone de disposiciones inherentes a la vida de los pueblos indígenas, razón por la cual el territorio es un derecho tan importante en la delimitación y el reconocimiento de sus derechos. De esta manera, se armoniza y habilita el espacio geográfico que se encuentra bajo la autoridad histórica cultural y el control político de un pueblo, lo que permite a su vez regular situaciones jurídicas que brindan seguridad en la toma de decisiones. También se reconoce que estas comunidades cuentan con culturas ancestrales y que el territorio está asociado a su cosmogonía, la cual se coliga a su organización social, con la ocupación y distribución adecuada de los recursos naturales.

Según Barabas (2004), el territorio para las comunidades indígenas es:

[...] territorio habitado y culturalmente construido por un grupo etnolingüístico a lo largo de la historia profunda. No solo provee la reproducción de la población, sino que en él se desarrollan relaciones de parentesco, culturales, lingüísticas y políticas. El etnoterritorio reúne las categorías de tiempo y espacio (historia en el lugar), y es soporte central de la identidad y la cultura porque integra concepciones, creencias y prácticas que vinculan a los actores sociales con los antepasados y con el territorio que estos les legaron. (pp. 108-109)

Adicionalmente, el Artículo 13 del Convenio 169, en su parágrafo 2, señala que: 
[...] la utilización del término tierras deberá incluir el concepto de territorios, lo que cubre la totalidad del hábitat de las regiones que los pueblos interesados ocupan o utilizan de alguna manera, de acuerdo con lo expuesto, el derecho a la tierra comprende participar en la utilización, administración y conservación de los recursos que le son propios, por lo tanto, la propiedad y posesión se refieren a las tierras y no al territorio, ocupación y utilización es sinónimo de uso y disfrute. (Gómez, 1998, p. 149)

\section{Usos y costumbres de los pueblos indígenas}

Como lo anota María Teresa Sierra (1997), el reconocimiento del sistema jurídico indígena es de índole internacional y nacional, según corresponda a cada Estado, de manera que es otro de los engranajes centrales de las pretensiones indígenas vinculadas a la demanda de autonomía y autodeterminación, pues las comunidades son titulares del derecho a la propiedad adquirido a partir de la apropiación originaria.

Es innegable que solo puede existir un derecho si hay una estructura que garantiza su satisfacción, por lo que el reconocimiento de la existencia de sistemas normativos, así como de formas particulares de control social, a partir de las cuales se regula la vida de los pueblos y se ejerce la autoridad, configuran la composición de

sistemas jurídicos gestados en relación continua con el orden jurídico dominante, que se han ido modificando y adecuando con el tiempo. Sin embargo, se suele considerar a estos sistemas como la expresión de un derecho tradicional, que ha logrado permanecer a través del tiempo. (Sierra, 1997, p. 135)

La Corte Constitucional de Colombia, en sentencias C-139 de 1996 y T-685 de 2015, ha sostenido que el Artículo 246 de la Constitución implica una serie de garantías para las comunidades indígenas, como la de reconocer autoridades judiciales propias; establecer y conservar normas y 
procedimientos; la sujeción a la Constitución y a la ley; la competencia del legislador para señalar la forma de coordinación de la jurisdicción especial indígena con el sistema nacional; y el no condicionamiento a la expedición de una ley adicional para gozar de los derechos enunciados.

La constitución reconoce y proclama la diversidad cultural, dando paso al reconocimiento de derechos básicos donde la diferencia se valore como un componente heterogéneo, en el respeto de los derechos de autonomía y pluralismo jurídico, en el uso de sus costumbres en la investigación, procedimiento y sanción de las conductas que distorsionan la convivencia armoniosa de los indígenas entre sí. (Herrán y García, 2010, p. 31)

$\mathrm{Al}$ respecto, en los artículos 1 y 7 de la Constitución Política de Colombia, se deja claro que el país es un Estado democrático, participativo, incluyente y pluralista que garantiza la diversidad étnica y cultural (C.P., 1991). De allí surge el fuero indígena como un derecho de cada uno de los miembros de las comunidades, que se adquiere por el hecho de pertenecer a estas y que radica en la posibilidad de ser juzgados por sus propias autoridades, con ajuste a sus normas y procedimientos, de acuerdo con sus usos y costumbres (Guarín, Olarte y Garzón, 2019).

En un contexto similar de jurisprudencia, vale la pena señalar las decisiones aludidas en el caso de la comunidad indígena yakye axa contra el Estado de Paraguay, en cuya sentencia proferida en 2005 se manifestaba lo siguiente:

[...] Debido a que el presente caso trata sobre los derechos de los miembros de una comunidad indígena, la Corte considera oportuno recordar que, de conformidad con los artículos 24 (Igualdad ante la Ley) y 1.1 (Obligación de Respetar los Derechos) de la Convención Americana, los Estados deben garantizar, en condiciones de igualdad, el pleno ejercicio y goce de los derechos de estas personas que están sujetas a su 
jurisdicción. Sin embargo, hay que resaltar que para garantizar efectivamente estos derechos, al interpretar y aplicar su normativa interna, los Estados deben tomar en consideración las características propias que diferencian a los miembros de los pueblos indígenas de la población en general y que conforman su identidad cultural. El mismo razonamiento debe aplicar la Corte, como en efecto lo hará en el presente caso, para valorar el alcance y el contenido de los artículos de la Convención Americana, cuya violación la Comisión y los representantes imputan al Estado. (Corte Interamericana de Derechos Humanos, 17 de junio de 2005, Sentencia caso comunidad indígena yakye axa vs.

Paraguay, párr. 51)

Jacqueline Blanco (2005) indica que en el orden jurídico de la pluriculturalidad se está frente a un proceso político de consensos en la región, que expresa sin duda una reivindicación en materia de reconocimiento de derechos. Asimismo, actualmente es indiscutible la voz y la participación que tienen los pueblos indígenas en las decisiones públicas relacionadas con sus derechos o aquellas que pasen por alto la diversidad cultural. Cada periodo histórico ha avanzado para que la inclusión de los indígenas sea una realidad.

Esta Corte ha considerado que el reconocimiento de derechos fundamentales a las comunidades indígenas tiene sustento en los principios de participación y pluralismo consagrados como fundantes del Estado en el Artículo $1^{0}$ superior; en el principio de respeto a la diversidad étnica establecido en el Artículo $7^{\circ}$ constitucional, y en el principio de igualdad entre culturas [...] En jurisprudencia temprana, explicó este Tribunal que el carácter fundamental de los derechos de los grupos indígenas se desprende de la prohibición de desaparición forzada llevada al plano de estos grupos humanos. Posteriormente, la Corte ha avanzado en la comprensión de los derechos de los pueblos aborígenes en el marco del DIDH y los mandatos de protección reforzada sentados 
por el constituyente frente a las comunidades indígenas. (Sentencia T

282 de 2011)

En conclusión, la relación de las comunidades indígenas con la tierra no se limita a la simple posesión y producción, sino que constituye un elemento material y espiritual básico de su cultura, fundamental para la conservación de su legado generacional. En línea con lo expuesto, la práctica de desconocimiento de la autodeterminación acorde con sus usos y costumbres pone en riesgo la herencia cultural de las naciones.

\section{Reconocimiento del pluralismo legal}

A partir de la Constitución Política de 1991, Colombia reconoce los derechos de los pueblos indígenas a ejercer formas culturalmente diferentes de justicia. De acuerdo con el texto nacional, en su Artículo 357, los resguardos indígenas se consideran municipios de propiedad colectiva sujetos de derecho. No obstante, al no existir una ley que coordine la jurisdicción especial indígena y el sistema judicial nacional, desde el punto de vista constitucional, los resguardos gozan de autonomía jurisdiccional, de modo tal que en el desarrollo jurídico y conceptual de esta jurisdicción se ha dado vía jurisprudencia por la Corte Constitucional para resolver los conflictos que han surgido en el ejercicio de los derechos individuales y colectivos (ONIC, 2009, p. 82).

La Corte ha desarrollado una línea doctrinal de núcleo básico fundamental de derechos a respetar destinada a las autoridades indígenas, donde se establecen aspectos como la prohibición de matar, torturar o esclavizar a cualquier miembro de su grupo, así como la obligación de garantizar un debido proceso conforme con su autonomía y costumbres.

[...] la Corte inicialmente se mostró abierta a "interpretar" el debido proceso y ciertas prácticas de acuerdo con criterios culturales, por 
ejemplo, al reconocer que el uso del fuete o látigo como sanción para los indígenas se puede interpretar como una práctica culturalmente específica, sancionada por el colectivo, más que como forma de tortura. (Sieder, 2011, p. 7)

Los límites constitucionales están dados por los artículos 1, 2, 7, 70 y 246 de la Constitución Política de Colombia de 1991. De esta manera, la Corte Suprema de Justicia identifica los elementos que sirven de sustento a la jurisdicción indígena: 1) elemento humano, grupo diferenciable por su origen étnico y su identidad cultural; 2) elemento orgánico, autoridades tradicionales con función de control social en sus comunidades; 3) elemento normativo, sistema jurídico propio conformado a partir de las prácticas y usos tradicionales; 4) elemento geográfico, la jurisdicción indígena remite al territorio, según el Artículo 329 "deberá conformarse con sujeción a la ley y delimitarse por el gobierno con participación de las comunidades"; y 5) congruencia, el orden jurídico tradicional y el sistema judicial nacional de estas comunidades no puede resultar contrario a la Constitución ni a la ley (Radicado 39444/13, 2013).

En este sentido, es importante recordar que no solo las garantías constitucionales limitan el ejercicio de los derechos de las comunidades indígenas, pues las normas que hacen parte del bloque constitucional colombiano articulan la protección de los derechos humanos de todos los habitantes del territorio nacional a través del Artículo 93 de la carta política.

Stavenhagen ilustra las costumbres indígenas que serían prohibidas bajo el imperio de los DDHH, con la clitoridectomía o mutilación genital femenina [...]. Y acá, ya hay algo sospechoso. Con todo lo que pudiese repugnar al pensamiento occidental una práctica de esta naturaleza, no parece coherente en un plano teórico - ni siquiera en uno puramente emotivo-, el desdiferenciar una amplia gama de tradiciones vernáculas 
indígenas - léase diferencias de género, gobiernos no democráticos, etc. -, subsumiéndolas uniformemente junto a la ablación de clítoris, el genocidio o la esclavitud, bajo el epígrafe de "violaciones a los derechos humanos". (Stavenhagen, 1992, citado por Carmona, 2009, p. 2)

Por consiguiente, la protección de los derechos de los indígenas es respetada desde una visión colectiva y no individual. No obstante, el distanciamiento de lo individual a lo grupal dificulta que en el interior de los pueblos indígenas se comprenda con precisión que proteger a la persona individualmente fortalece la seguridad misma del grupo, considerado culturalmente.

En consecuencia, Will Kymlicka (1996), citado por Herrán Pinzón (2009, p. 191), expone:

[...] intenta demostrar que la teoría liberal no debe defender solo los derechos de los individuos, sino también los derechos de los diferentes grupos culturales, sostiene que una teoría liberal de los derechos de las minorías debe explicar cómo coexisten los derechos de las minorías con los derechos humanos.

En conclusión, los límites a la protección de los derechos de los pueblos indígenas están enmarcados en la Constitución Política de Colombia, que a su vez se encuentra relacionada con la normativa internacional a partir de lo establecido en el Artículo 93, donde para garantizar la subsistencia de los pueblos indígenas se debe respetar al individuo como fundamento esencial en la conservación de la identidad cultural.

\section{Derechos humanos y mujeres indígenas}

Desde la concepción del amparo y el respeto de los derechos humanos y de la igualdad de las personas - concretamente entre hombre y mujer-, actualmente se diseñan modelos de interculturalidad que permitan 
construir nuevos contextos para los pueblos indígenas, en especial para las mujeres de estas comunidades: 1) la Convención sobre la eliminación de todas las formas de discriminación contra la mujer, Resolución 34/180 del 18 de diciembre de 1979; 2) el Protocolo facultativo de la Convención sobre la eliminación de todas las formas de discriminación contra la mujer, Resolución A/54/4 del 6 de octubre de 1999; 3) la Convención de Belém do Pará, convención interamericana para prevenir, sancionar y erradicar la violencia contra la mujer; 4) la Convención sobre los derechos políticos de la mujer, adoptada por la Asamblea General de las Naciones Unidas, Resolución 640 (VII), del 20 de diciembre de 1952; y 5) la Cuarta Conferencia Mundial de las Naciones Unidas sobre la Mujer, que tuvo lugar en Beijing, China, sobre la eliminación de la violencia contra la mujer, realizada del 4 al 15 de septiembre de 1995.

En la actualidad las mujeres indígenas luchan por sus derechos en sus territorios, destacan sus condiciones actuales y cuestionan las tradiciones que las excluyen, mientras que en el contexto internacional denuncian "las violaciones a sus derechos como mujeres y como integrantes de sus pueblos indígenas en el contexto sociopolítico y económico nacional e internacional" (Valladares de la Cruz, 2008, p. 49).

La representación de los indígenas en los órganos legislativos ha tenido una relevancia específica en los procesos de transición y consolidación democrática en América Latina (Sonnleitner, 2012, p. 7). En los últimos veinte años se ha observado un adelanto en el reconocimiento de los derechos sociales, civiles, políticos y de género en las comunidades, y, aunque de forma más lenta, se han logrado conquistas importantes para las mujeres indígenas, ha habido un avance continuo para garantizar el derecho a su libre locomoción, al voto y a ser elegidas democráticamente. Entretanto, en el contexto del derecho de las mujeres indígenas a expresar sus diferencias culturales y de género, varias han accedido a cargos de 
representación política, como por ejemplo Deborah Haaland, de 57 años, y Sharice Davids, de 38, quienes entraron al Congreso de Estados Unidos, nación que nunca antes había tenido congresistas indígenas en sus más de 230 años de historia. Asimismo, Ati Seygundiba, conocida como Ati Quigua, indígena de la Sierra Nevada de Santa Marta, se convirtió en la primera concejal indígena de Colombia el 3 de enero de 2004, electa para los periodos 2004-2007, 2008-2011 y 2020-2023. Además, Eulalia Yagarí, proveniente del pueblo embera chami, fue la primera mujer indígena diputada de la Asamblea de Antioquia, durante los periodos 1998 y 2003. La participación política de los pueblos indígenas, en especial de las mujeres indígenas, se encuentra manifiesta en el Artículo 5 de la Declaración de las Naciones Unidas sobre los Derechos de los Pueblos Indígenas (ONU, 2007): "Los pueblos indígenas tienen derecho a conservar y reforzar sus propias instituciones políticas, jurídicas, económicas, sociales y culturales, manteniendo a la vez su derecho a participar plenamente, si lo desean, en la vida política, económica, social y cultural del Estado”. Asimismo, el Artículo 18 establece que:

[...] los pueblos indígenas tienen derecho a participar en la adopción de decisiones en las cuestiones que afecten a sus derechos, por conducto de representantes elegidos por ellos de conformidad con sus procedimientos, así como a mantener y desarrollar sus propias instituciones de adopción de decisiones. (ONU, 2007)

Las voces de las mujeres indígenas de Colombia, Perú, Nicaragua, Guatemala, entre otros países, han sido fundamentales para denunciar las infracciones y los abusos cometidos por distintos actores legales e ilegales. En este sentido, su organización comunitaria ha asumido la responsabilidad de sacar a sus familias adelante, debido a la desaparición de sus esposos, hermanos o familiares. En las tres últimas décadas se 
observa que cada vez más las mujeres hacen parte activa de la política (Valladares de la Cruz, 2008, p. 63).

La Declaración de las Naciones Unidas (2007) establece las pautas mínimas de los siguientes derechos en igualdad de condiciones, tanto para los hombres como para las mujeres indígenas, y articula varias dimensiones, tales como: 1) la no discriminación; 2) la integridad cultural; 3) la propiedad, uso, control y acceso a las tierras y recursos; 4) el desarrollo y bienestar social; y 5) la participación política. A su vez, estos derechos se refuerzan con el Artículo 44 (ONU, 2007, énfasis añadido): "Todos los derechos y las libertades reconocidos en la presente Declaración se garantizan por igual al hombre y a la mujer indígenas", y el Artículo 21: "En la aplicación de la presente Declaración se prestará particular atención a los derechos y necesidades especiales de los ancianos, las mujeres, los jóvenes, los niños y las personas con discapacidad indígenas" (ONU, 2017, énfasis añadido).

Un antecedente frente a la proclama de la voz de la mujer indígena se puede encontrar en El derecho de la mujer indígena en Colombia: manifiesto de catorce mil mujeres lamistas, documento que apareció en el municipio de Girardot (Cundinamarca) el 18 de mayo de 1927, como primera publicación del Movimiento de Mujeres Indígenas que surgió de la inspiración y dirección del líder indígena Manuel Quintín Lame. En ese texto se puede identificar cómo la mujer indígena hace un llamado de justicia a la civilización del país:

Nos dirigimos a todas las sociedades del sexo femenino religioso, como son a las hermanas de la caridad, a las monjas, a las madres, etc., a las señoritas y señoras directoras de todos los colegios y universidades del país, [para] que conozcan las injusticias y que hoy ya el sexo indígena femenino en Colombia levantó el grito para defender de hecho sus propiedades materiales y morales que a nuestros varones les han sido 
arrebatadas, y para no errar nos dirigimos a todas las sociedades del sexo femenino del país y que nos digan si esto es justo o no [...] En constancia firmamos más de catorce mil mujeres indígenas de siete departamentos e invitamos a coadyuvar con nuestras ideas al proletariado colombiano de indígenas, pues haremos flotar nuestras banderas de paz en las tremendas campañas ante la injusticia y el error que cometen diariamente los opresores de categoría. (Sánchez, 2010, p. 29)

En línea con lo anterior, fallos judiciales como el "Caso González y otras ('Campo Algodonero') vs. México”, sentencia del 16 de noviembre de 2009 (Corte Interamericana de Derechos Humanos, 2009), reconocen que una cultura arraigada en estereotipos, donde el supuesto de la inferioridad de las mujeres no se transforma de un día para otro, sino que depende del cambio de modelos culturales, se alza como una tarea difícil para cualquier Estado. Sin embargo, este propósito no solo le corresponde al Gobierno central, sino que también las comunidades deben trabajar al interior de sus pueblos para reconciliar sus creencias y prácticas ancestrales, vinculadas a la protección de valores supremos como la vida, y su relación con la figura de la mujer.

\section{Discriminación y racismo}

Como se dijo anteriormente, el cambio de modelos culturales es una tarea bastante difícil para un Estado, prueba de ello se puede evidenciar en el Artículo 38 del Código Penal Colombiano expedido en 1936, que contemplaba:

[...] Cuando homicidio o las lesiones se cometan por cónyuge, padre o madre. Hermano o hermana contra el cónyuge, la hija o la hermana de vida honesta, a quienes sorprenda en legítimo acceso carnal. O contra el copartícipe de tal acto, se impondrán las respectivas sanciones de que tratan los dos Capítulos anteriores, disminuidas de la mitad a las tres cuartas partes. 
Lo dispuesto en el inciso anterior se aplicará al que en estado de ira o de intenso dolor, determinados por tal ofensa, cometa el homicidio o cause las lesiones en las personas mencionadas, aun cuando no sea en el momento de sorprenderlas en el acto carnal. Cuando las circunstancias del hecho demuestren una menor peligrosidad en el responsable, podrá otorgarse a este el perdón judicial. (Ley 95 de 1936, art. 38, Colom.)

El contenido de esta disposición legal muestra la manera como el sentimiento social ha impugnado desde mucho tiempo atrás el adulterio de la mujer, mientras se defiende la autoridad marital que recae en el hombre.

La opresión de la mujer por el hombre, su precaria situación en la vida social y doméstica, se ha reflejado en el derecho; el hombre ha sido el amo y la mujer su sierva. Ella se considera depositaria de todos los deberes, él lo ha sido de todas las prerrogativas. Por lo tanto, las concepciones moralistas desiguales en la concepción de hombre y mujer exageran la gravedad del adulterio de la mujer, mientras se conciben con tolerancia y benevolencia las relaciones de infidelidad del hombre.

En 1907 el general Uribe Uribe en erudito discurso dijo que la mejor manera de reducir los salvajes a la civilización era, siguiendo el ejemplo de españoles y portugueses, domesticar [a] los indígenas [...] En nuestra condición de raza conquistadora, ya que arrebatamos el suelo al indio y que cada día vamos estrechándolo para lo más recóndito de las selvas, tenemos obligación - si de veras somos cristianos - de arrancarlos a la barbarie en la que viven, para traerlos a la comunión de la fe, del trabajo y de la sociedad. De seguro que la providencia no creó al indio para conservarle segregado del movimiento general del progreso humano. (Herrán, 2009, p. 200)

Por otro lado, siguiendo la especificidad de la Ley 89 de 1890 respecto a cómo deben ser gobernados los salvajes - entiéndase como los indígenas- 
para que vayan "reduciéndose" a la vida civilizada, el Artículo 4 establece que:

En todo lo relativo al Gobierno económico de las parcialidades tienen los pequeños Cabildos todas las facultades que les hayan transmitido sus usos y estatutos particulares, con tal que no se opongan a lo que previenen las leyes, ni violen las garantías de que disfrutan los miembros de la parcialidad en su calidad de ciudadanos. (Ley 89 de 1890 art. 4, Colom.)

Puede concluirse con esto que en la normativa se divulga el respeto de los derechos de las personas en su calidad de ciudadanos - en el sentido estereotipado en que los consideraba la ley-. Cabe mencionar que no todas las personas gozaban del atributo de ciudadanía, pues eran precisas ciertas características para que alguien se elevara a esta posición. Por ejemplo, en la Constitución de Antioquia, un ciudadano era aquel hombre responsable:

[...] ante la familia, y por supuesto, su relación con la Iglesia; el ciudadano era tenido como un hombre íntegro, de reconocidas cualidades políticas, sociales y morales: ninguno es buen ciudadano si no es buen padre, buen hijo, buen hermano, buen amigo y buen esposo. La ciudadanía no será por lo tanto un sujeto abstracto y universal libre de ataduras, sino un varón que responda a una condición social y económica concreta. (Blanco, 2009, p. 148)

En este contexto, es claro que los derechos de la mujer, en general, y de las mujeres indígenas, en particular, han sido hasta la actualidad dos procesos en constante desarrollo. Asimismo, abordar el tema de la mujer indígena sin duda conlleva discusiones locales, nacionales e internacionales frente a los usos y las costumbres ancestrales, que en su mayoría son de estirpe machista. 
Como aporte a este debate, queremos destacar la publicación del periódico El Tiempo del 22 de marzo de 2007, titulada: "A unas 8000 indígenas embera chamí les han cortado el clítoris”, que afirma frente a esta práctica:

[...] Para el historiador Víctor Zuluaga, que ha estudiado a profundidad los pueblos embera que habitan Risaralda, se trata de un tema sagrado que se basa en la creencia de que una de las maneras para evitar el fin del mundo (pues se le podría caer de las manos a su dios Karabi), las mujeres deben evitar moverse durante el acto sexual, lo cual se garantiza extirpando su clítoris con una cuchilla o una puntilla caliente.

\section{[...] Rubén Guasarabe, líder indígena de Risaralda}

Se trata de una práctica que viene de los ancestros indígenas. Dentro de la comunidad embera es algo sagrado que hay que conocer para poder criticar. Los líderes indígenas están dispuestos a analizar el tema para evitar que se abuse de los derechos humanos de las niñas, pero no se puede eliminar el tema cultural y el principio de autonomía indígena. Con este procedimiento se busca que las mujeres de la comunidad no les sean infieles a sus esposos. (Redacción El Tiempo, 2007, énfasis añadido)

En correspondencia con el respeto a la mujer indígena, a su integridad personal y a su libertad sexual, los convenios ratificados por Colombia se han venido articulando en el acatamiento de las normativas para que estos sean respetados. Como parte de la controversia sobre la ablación, el 11 de septiembre de 2017 indígenas embera chami de 18 municipios del Valle del Cauca se comprometieron a eliminar esta práctica ancestral con sus mujeres (Lozano, 2017).

La abolición de esta práctica ancestral que aún se realizaba en América Latina sirvió como referente internacional en la lucha de los derechos de las mujeres. La sensibilización en cada uno de los territorios indígenas y el derecho a la igualdad entre hombre y mujer indígena, así como el respeto a 
su integridad y formación sexual, fueron fundamentales para que se llegara a esta decisión histórica de la comunidad.

Por consiguiente, los derechos de la mujer indígena consagrados en los instrumentos internacionales y adoptados por cada uno de los países que aún ejercen la práctica de la mutilación genital femenina, constituyen un marco normativo fundamental para contrarrestar estas formas de exclusión a las que han sido sometidas.

Dado que todavía no se tiene registro exacto de cuándo y dónde comenzó esta práctica, la Conferencia de El Cairo de 1994 destaca la necesidad de satisfacer los derechos individuales de las mujeres de forma particular. Asimismo, en la Convención de Belém do Pará, se determinó que esta tradición es una violación de los derechos humanos y de las libertades fundamentales, y que además limita total o parcialmente a la mujer en su reconocimiento, goce y ejercicio.

Adicionalmente, las conferencias sobre la mujer realizadas por la ONU en 1976, 1980 y 1985, y la Cuarta Conferencia Mundial de las Naciones Unidas sobre la Mujer, celebrada en Beijing, China, sobre la eliminación de la violencia contra la mujer, materializaron un plan de acción para eliminar todas las formas de discriminación contra la mujer y la niña, además de suprimir los obstáculos jurídicos y culturales para el avance en el respeto de sus derechos sexuales y reproductivos.

Entretanto, la Organización Mundial de la Salud (OMS, 2018) se sitúa en una posición similar a la establecida en la definición de la salud sexual y reproductiva realizada por la Asamblea General de las Naciones Unidas sobre los derechos reproductivos y sexuales de la mujer, en la cual se hace referencia a la mutilación genital femenina, el placer, el sexo, entre otros temas relacionados. 
En conclusión, la necesidad de reconocimiento universal del derecho a la sexualidad va más allá de la concepción reproductiva, pues el debate entre derechos humanos y universales o derechos de las comunidades indígenas debe ser un cuestionamiento que en la actualidad haga énfasis en la premisa de que los Estados son garantes de la vida e integridad de las personas, los pueblos y sus culturas, teniendo como piedra angular entre los actores la dignidad humana y la vida en correlación con el derecho a las libertades individuales. Así pues, tales horizontes requieren por parte de los gobiernos conjugar las distintas justicias y hacer efectiva la igualdad entre sujetos, tanto individuales como colectivos (Aparicio, 2011, p. 30). El multiculturalismo sustenta la producción y administración de la diferencia dentro del orden nacional al hacerla funcional (Walsh, 2008, p. 141), por lo tanto, gobernar desde esta concepción contempla matices como la diversidad de los "discursos y las prácticas de los Estados para gestionar la multietnicidad de las sociedades nacionales y, por otro lado, la gestión de la diversidad (étnica, política, religiosa, ideológica, de edad y de género) que enfrentan los gobiernos indígenas en sus jurisdicciones" (Burguete, 2008, p. 16).

Consecuentemente, los usos y las costumbres de los pueblos indígenas deben avanzar hacia un nuevo Estado multicultural, donde resulta inexorable realizar cambios jurídicos que eviten la desaparición de estas comunidades, a la que habían sido condenadas, en especial las mujeres indígenas, al no ser tenidas en cuenta en los proyectos legislativos. Por último, estas iniciativas se deben sustentar en el paradigma de un Estado en el que se rechace la creciente automatización de las comunidades indígenas y se aliente la protección de sus derechos y el aseguramiento de sus garantías constitucionales. 


\section{Conclusiones}

Como se observa, a pesar de los grandes adelantos en América Latina en el reconocimiento jurídico de los pueblos indígenas y de sus derechos, perduran numerosos inconvenientes para asegurar su eficacia. De modo que la falla estructural que persiste hasta la actualidad en las sociedades latinoamericanas muestra cómo los problemas de articulación entre estas comunidades y el ordenamiento jurídico interno de cada nación son una forma de distanciar las culturas existentes en los territorios.

Asimismo, aunque no se niega la validez y legitimidad de las tradiciones, costumbres, cultura e historia indígenas, no obstante, se debe repensar su identidad de una forma mucho más fluida, sin miedo a que se pierda la capacidad de cambio que han tenido para afrontar las nuevas realidades. Con seguridad en los presentes planteamientos se abren alternativas de discusión al pensar en espacios amplios de interacción interétnica, más allá de cualquier contexto local o regional. Sin embargo, la respuesta debe estar dirigida a contribuir a la visión indígena y la protección de sus derechos.

En el caso de las poblaciones indígenas, la equidad supone, necesariamente, la adopción de una perspectiva intercultural en la que se reconozcan sus derechos civiles, políticos, económicos, sociales y culturales desde una óptica de igualdad de derechos de las personas que habitan estas comunidades.

Las desigualdades son el resultado de la discriminación estructural. Por esto es necesario que el análisis de la información sociodemográfica se contextualice en términos históricos, territoriales y de género. Solo así será posible trazar y emplear políticas y programas oportunos y eficaces, destinados a cumplir con las obligaciones internacionales asumidas por los gobiernos en materia de equidad, libertad sexual e igualdad de género. 
Los logros alcanzados por las mujeres indígenas en las últimas tres décadas muestran un adelanto considerable en el reconocimiento real de sus derechos, resultado de conflictos con Estados y sociedades en cuya órbita se han ganado libertades parciales, transitorias. El objetivo principal de estos esfuerzos es la articulación consensuada de usos y costumbres a partir del respeto continuo de los derechos de las personas en general. Así se puede lograr un cambio constante de la población indígena en América Latina, que definirá su lucha y construirá el progreso de sus derechos con justicia de género.

Es posible cambiar las prácticas de mutilación genital femenina teniendo en cuenta que atentan contra los derechos de las mujeres indígenas, catalogadas en la actualidad titulares de derechos en igualdad de condiciones que las mujeres de otros grupos poblacionales. Además, los derechos de los pueblos indígenas en la actualidad gozan de herramientas para hacerlos valer, no obstante, las normativas, tanto internas de los países como en el campo internacional, son enfáticas en que la autonomía no puede ir en contravía de los derechos humanos en la protección de la dignidad humana de las personas que conforman estas comunidades, como los niños, las niñas, las mujeres y los ancianos.

\section{Referencias}

Aparicio, M. (2011). Pueblos indígenas y constitucionalismo: de la igualdad multicultural al diálogo entre iguales. En Los derechos de los pueblos indígenas a los recursos naturales y al territorio. Conflictos y desafios en América Latina (pp. 7-30). Icaria.

Assies, W. (2000). La situación de los Derechos Humanos de los pueblos indígenas en el contexto Latinoamericano. [Ponencia]. 2000. Unidos en la diversidad por nuestro derecho al territorio. Programa de Pueblos Indígenas del Ministerio de Justicia y Derechos Humanos. Santa Cruz, Bolivia. http://www.alertanet.org/dc-willemdhypi.htm 
Bahamón Jara, M. L. (2020). Protección mixta de los derechos humanos en la Corte Constitucional de Colombia en relación con los derechos de los pueblos indígenas: el principio pro homine como centro de gravedad. Via Inveniendi et Iudicandi, 15(1), 247-284. https://doi.org/10.15332/19090528/5749

Barabas, A. (2004). La territorialidad simbólica y los derechos territoriales indígenas: reflexiones para el Estado pluriétnico. Alteridades, 14(27), 105-119. https://www.redalyc.org/articulo.oa?id=74702706

Blanco, B. (2005). Colombia multicultural. Historia del derecho a la inclusión. Diálogos de Saberes, (22), 81-94. https://revistas.unilibre.edu.co/index.php/dialogos/article/view/3932/3307

Blanco, B. (2009). Los derechos civiles y políticos en la historia constitucional colombiana. Novum Jus, 3(1), 133-160. https://novumjus.ucatolica.edu.co/article/download/883/910/

Burguete, A. (2008). Gobernar en la diversidad en tiempos del multiculturalismo en América Latina. En X. Leyva, A. Burguete y S. Speed (coords.), Gobernar (en) la diversidad: experiencias indígenas desde América Latina. Hacia la investigación de co-labor (pp. 15-64). Centro de Investigaciones y Estudios Superiores en Antropología Social (Ciesas).

Carmona, C. (2009). Pueblos indígenas y la tolerancia occidental. Los derechos humanos como forma sublimada de asimilación. Polis. Revista Latinoamericana, 23, 1-18. https://journals.openedition.org/polis/1736\#text

Comisión Económica para América Latina y el Caribe [Cepal]. (2010). Propuesta de indicadores para el seguimiento de las metas de la Conferencia Internacional sobre la Población y el Desarrollo en América Latina y el Caribe. Organización de las Naciones Unidas.

Corte Constitucional de Colombia [C.C.], abril 9, 1996, M.P.: C. Gaviria Díaz, Sentencia C139, [Colom.].

Corte Constitucional de Colombia [C.C.], noviembre 4, 2015 M.P.: M. A. Roldán, Sentencia T-685, [Colom.].

Corte Constitucional de Colombia [C.C.], noviembre 7, 2007, M.P.: C. I. Vargas Hernández, Sentencia C-921, [Colom.]. 
Corte Constitucional de Colombia [C.C.], abril 12, 2011, M.P.: L. E. Vargas, Sentencia T282 [Colom.].

Corte Interamericana de Derechos Humanos. (2005, 17 de junio). Sentencia Caso Comunidad indígena Yakye Axa vs. Paraguay. https://www.corteidh.or.cr/docs/casos/articulos/seriec 125 esp.pdf

Corte Interamericana de Derechos Humanos. (2009, 16 de noviembre). Sentencia del Caso González y otras (“Campo Algodonero”) vs. México. https://www.corteidh.or.cr/docs/casos/articulos/seriec 205 esp.pdf

Corte Suprema de Justicia de Colombia [C.S.J.], febrero 13, 2013. M.P.F.A.Castro Caballero Radicado 39444 [Colom.].

Cujabante, V. (2014). Los pueblos indígenas en el marco del constitucionalismo latinoamericano. Revista Análisis Internacional, 5(1), 209-230.

Gómez, R. (1998). El derecho indígena frente al espejo de América Latina. Revista IIDH, 26, 47-79. https://www.corteidh.or.cr/tablas/ro6841-2.pdf

Guarín Ramírez, E., Olarte López, L. y Garzón Barrera, J. (2019). El pluralismo social en la jurisprudencia de la Corte Constitucional colombiana y sus efectos en la materialización de los derechos. Via Inveniendi et Iudicandi, 14(2), 11-34.

Herrán, O. (2009). Las minorías étnicas colombianas en la Constitución Política de 1991. Prolegómenos. Derechos y Valores, 12(24), 189-212. https://www.redalyc.org/pdf/876/87617269013.pdf

Herrán, O. y García, G. (2010). Identidad judicial indígena frente a la jurisdicción ordinaria actual en Colombia. Prolegómenos. Derechos y Valores, 13(26), 29-42. https://revistas.unimilitar.edu.co/index.php/dere/article/view/2419

Houghton, J. (2008). Desterritorialización y pueblos indígenas. En J. Houghton (ed.), La Tierra contra la muerte. Conflictos territoriales de los pueblos indígenas en Colombia (pp. 83-176). Centro de Cooperación al Indígena (Cecoin).

Kymlicka, W. (1996). Ciudadanía multicultural. Paidós.

Lozano, D. (2017, 11 de septiembre). Indígenas embera chamí, comprometidos a erradicar la ablación genital femenina. Gobernación del Valle del Cauca. https://www.valledelcauca.gov.co/equidad/publicaciones/39222/ndgenas ember a cham comprometidos a erradicar la ablacin de comunidad/

Revista IUSTA

ISSN: 1900-0448 | e-ISSN: 2500-5286 | DOI: https://doi.org/10.15332/25005286

N. 055 | julio-diciembre del 2021 
Normatividad Constitución Política de Colombia. (1991). Gaceta Constitucional No. 116 Resolución 34/180. (1979). Convención sobre la eliminación de todas las formas de discriminación contra la mujer.

Oficina del Alto Comisionado de las Naciones Unidas para los Derechos Humanos [Acnudh]. (s. f.). Pacto Internacional de Derechos Civiles y Políticos. https://www.ohchr.org/Documents/ProfessionalInterest/ccpr_SP.pdf

Organización de las Naciones Unidas [ONU]. (2007). Declaración Americana sobre los Derechos de los Pueblos Indígenas. https://www.acnur.org/fileadmin/Documentos/BDL/2008/6030.pdf?view=1

Organización de las Naciones Unidas [ONU]. (2008). Declaración de las Naciones sobre los Derechos de los Pueblos Indígenas. https://www.un.org/esa/socdev/unpfii/documents/DRIPS es.pdf

Organización de las Naciones Unidas [ONU]. (1945 [2020]). Carta de las Naciones Unidas (capítulo XVI). https://www.un.org/es/sections/un-charter/chapterxvi/index.html

Organización de las Naciones Unidas para la Educación, la Ciencia y la Cultura [Unesco]. (2004). La conclusión universal de la educación primaria en América Latina: estamos realmente tan cerca. Unesco, Oficina Regional para América Latina y el Caribe.

Organización de los Estados Americanos [OEA]. (2016, 15 de junio). Fin a 17 años de espera para los Pueblos Indígenas.

https://www.oas.org/es/centro_noticias/comunicado_prensa.asp?sCodigo=C$\underline{075 / 16}$

Organización Internacional del Trabajo [OIT]. (2014). Convenio 169 de la OIT sobre Pueblos Indígenas y Tribales. Declaración de las Naciones Unidas sobre los Derechos de los Pueblos Indígenas. https://www.ilo.org/wcmsp5/groups/public/--americas/---ro-lima/documents/publication/wcms 345065.pdf

Organización Internacional del Trabajo [OIT]. (s. f.). C107-Convenio sobre poblaciones indígenas y tribuales, 1957 (núm. 107). https://www.ilo.org/dyn/normlex/es/f?p=NORMLEXPUB:12100:0::NO::P12100 ILO CODE:C107

Revista IUSTA

ISSN: 1900-0448 | e-ISSN: 2500-5286 | DOI: https://doi.org/10.15332/25005286

N. 055 | julio-diciembre del 2021 
Organización Nacional Indígena de Colombia [ONIC]. (2009). Los derechos de los pueblos indígenas y tribales en la práctica. Programa para promover el Convenio núm. 169 de la OIT. https://www.ilo.org/wcmsp5/groups/public/---ed norm/--normes/documents/publication/wcms_113014.pdf

Organización Mundial de la Salud [OMS]. (2018). La salud sexual y su relación con la salud reproductiva: un enfoque operativo.

https://apps.who.int/iris/bitstream/handle/10665/274656/9789243512884spa.pdf

Redacción El Tiempo. (2007, 22 de marzo). A unas 8.00o indígenas embera chamí les han cortado el clítoris. El Tiempo.

https://www.eltiempo.com/archivo/documento/CMS-3488858

Resolución A/54/4. (1999). Protocolo Facultativo de la Convención sobre la eliminación de todas las formas de discriminación contra la mujer. https://www.ohchr.org/sp/professionalinterest/pages/opcedaw.aspx

Resolución 640. (1952). Convención sobre los derechos políticos de la mujer. https://www.acnur.org/fileadmin/Documentos/BDL/2001/0019.pdf?file=fileadmi n/Doc\#: :text=Las\%20mujeres\%20tendr\%C3\%A1n\%20derecho\%20a,los\%20hom bres\%2C\%20sin\%2odiscriminaci\%C3\%B3n\%20alguna.\&text=Las\%2omujeres\%20 ser\%C3\%A1n\%20elegibles\%2opara,los\%20hombres\%2C\%20sin\%2odiscriminaci\% C3\%B3n\%20alguna

Sánchez, G. (2010). Documentos para la historia del movimiento indígena colombiano contemporáneo. Biblioteca básica de los pueblos indígenas de Colombia. Ministerio de Cultura.

Sieder, R. (2011). Pueblos indígenas y derecho(s) en América Latina. En C. Rodríguez (coord.), El derecho en América Latina. Un mapa para el pensamiento jurídico del siglo XXI (pp. 303-322). Siglo XXI.

Sierra, M. T. (1997). Esencialismo y autonomía: paradojas de las reivindicaciones indígenas. Alteridades, 7(14), 131-143. https://www.redalyc.org/pdf/747/74745549009.pdf

Sonnleitner, W. (2012). La representación legislativa de los indígenas en México: de la representatividad descriptiva a una representación de mejor calidad. Tribunal Electoral del Poder Judicial de la Federación.

Revista IUSTA

ISSN: 1900-0448 | e-ISSN: 2500-5286 | DOI: https://doi.org/10.15332/25005286

N. ${ }^{0} 55$ | julio-diciembre del 2021 
Stavenhagen, R. (2004). Derechos humanos y pueblos indígenas: tendencias internacionales y contexto chileno. Universidad de La Frontera.

Valladares de la Cruz, L. (2008). Los derechos humanos de las mujeres indígenas. De la aldea local a los foros internacionales. Alteridades, 18(35), 47-65.

http://www.scielo.org.mx/pdf/alte/v18n35/v18n35a5.pdf

Walsh, C. (2008). Interculturalidad, plurinacionalidad y decolonialidad. Las insurgencias político-epistémicas de refundar el Estado. Tabula Rasa, 9, 131-152.

http://www.scielo.org.co/pdf/tara/ng/ngaog.pdf 